\title{
Two unusual complications after surgical interruption of an accessory pathway
}

\author{
Emile C Cheriex, Joep L R M Smeets, Hein J J Wellens
}

\begin{abstract}
In a patient with the Wolff-ParkinsonWhite syndrome, Ebstein's anomaly of the tricuspid valve, a right atrial Chiari net and a patent foramen ovale two unusual complications developed after surgical epicardial dissection combined with cryoablation of the anomalous pathway.

The first complication was that ablation of the right atrial wall led to changes in interatrial pressure gradients and the development of a right to left shunt necessitating surgical closure of the atrial septal defect. The second complication was the development of a thrombotic mass in the Chiari net simulating on intracavity tumour, which also had to be removed surgically.
\end{abstract}

(Br Heart f 1993;70:471-473)

Two unusual complications occurred after surgery for the Wolff-Parkinson-White syndrome in a patient with Ebstein's anomaly of the tricuspid valve with a patent oval foramen who had recurrent circus movement tachycardias through a right-sided accessory atrioventricular pathway.

\section{Case report}

A 19 year old man was examined in 1981 because of Wolff-Parkinson-White syndrome and circus movement tachycardia. Echocardiography showed Ebstein's anomaly of the tricuspid valve. The septal leaflet was attached $3 \mathrm{~cm}$ apical to the attachment of the mitral valve, so that the ratio of the atrialised part of the right ventricle to the ventricular part of right ventricle was 1:1. Echocardiography also showed an aneurysm of the interatrial septum, indicating patency of the foramen ovale. A Chiari network was clearly present in the right atrium. An electrophysiological study proved the presence of a right lateral accessory atrioventricular connection. During catheterisation it was possible to cross the foramen ovale. Oximetry showed no shunt at the atrial level (saturations: superior vena cava $76 \%$, inferior vena cava $82 \%$, right atrium $77 \%$, pulmonary artery $77 \%$, pulmonary veins and left atrium $97 \%$ and left ventricle $96 \%$ ). The patient's exercise tolerance was normal and no cyanosis was noticed during exercise.

In January 1989 poorly controlled tachycardia prompted epicardial dissection combined with cryoablation of his accessory connection without the use of extracorporal circulation. Postoperatively the patient had significant systemic arterial undersaturation, believed to be caused by central shunting.

A transoesophageal echocardiogram showed a freely moving flap valve of the foramen ovale and contrast echocardiography showed right to left shunting. The right lateral part of the right atrium above the annulus fibrosis appeared completely akinetic for almost $3 \mathrm{~cm}$. The shunting was thought to be mainly the result of a change in pressure gradient between right and left atrium. Rightsided catheterisation was performed during mechanical ventilation. The mean right atrial pressure was $14 \mathrm{~mm} \mathrm{Hg}$ and mean left atrial pressure was $7 \mathrm{~mm} \mathrm{Hg}$.

The oxygen saturations were as follows: superior vena cava $51 \%$, inferior vena cava $53 \%$, right atrium $50 \%$, pulmonary artery $53 \%$, pulmonary veins $98 \%$, left atrium $47-95 \%$ depending upon the sampling site, and left ventricle and aorta $85 \%$. These values indicated considerable right to left shunting in a patient whose general condition was deteriorating. The patient was operated on and the atrial defect was closed successfully. Recovery was uneventful and an echocardiographic investigation one week after the second operation showed no signs of shunting or other additional abnormalities. At routine follow up six months later echocardiography showed a large partially mobile tumour in the right atrium. Because this tumour seemed to be connected to the Chiari network a venous thrombus entrapped in the Chiari network was diagnosed (figs 1 and 2). After three weeks treatment with intravenous heparin the tumour did not decrease in size. Indium-III labelling of platelets did not show any activity in the right atrium and venous system, suggesting absence of active thrombus formation. Reoperation was performed and the thrombus was removed together with the Chiari network. The postoperative course was uneventful and the patient is currently symptom free.

\section{Comment}

Ebstein's anomaly of the tricuspid valve is an uncommon congenital abnormality, characterised by apical displacement of the septal leaflet of the structurally abnormal tricuspid valve into the right ventricle without displacement of the annulus fibrosis. WolffParkinson-White syndrome is reported to occur in $5-25 \%$ of patients with Ebstein's disease. ${ }^{1-5}$ An atrial septal defect or patent foramen ovale was reported in $60-80 \% .{ }^{126}$ Right to left shunting through the defect causes variable degrees of cyanosis in $60-80 \%$ of 
Figure 1 Transthoracic echocardiogram

(parasternal short axis)

showing the Chiari

network $(C)$ in the right atrium $(R A)$ and its

relation to the inferior vena cava (VCI). The atrial septal defect was closed during the second operation.

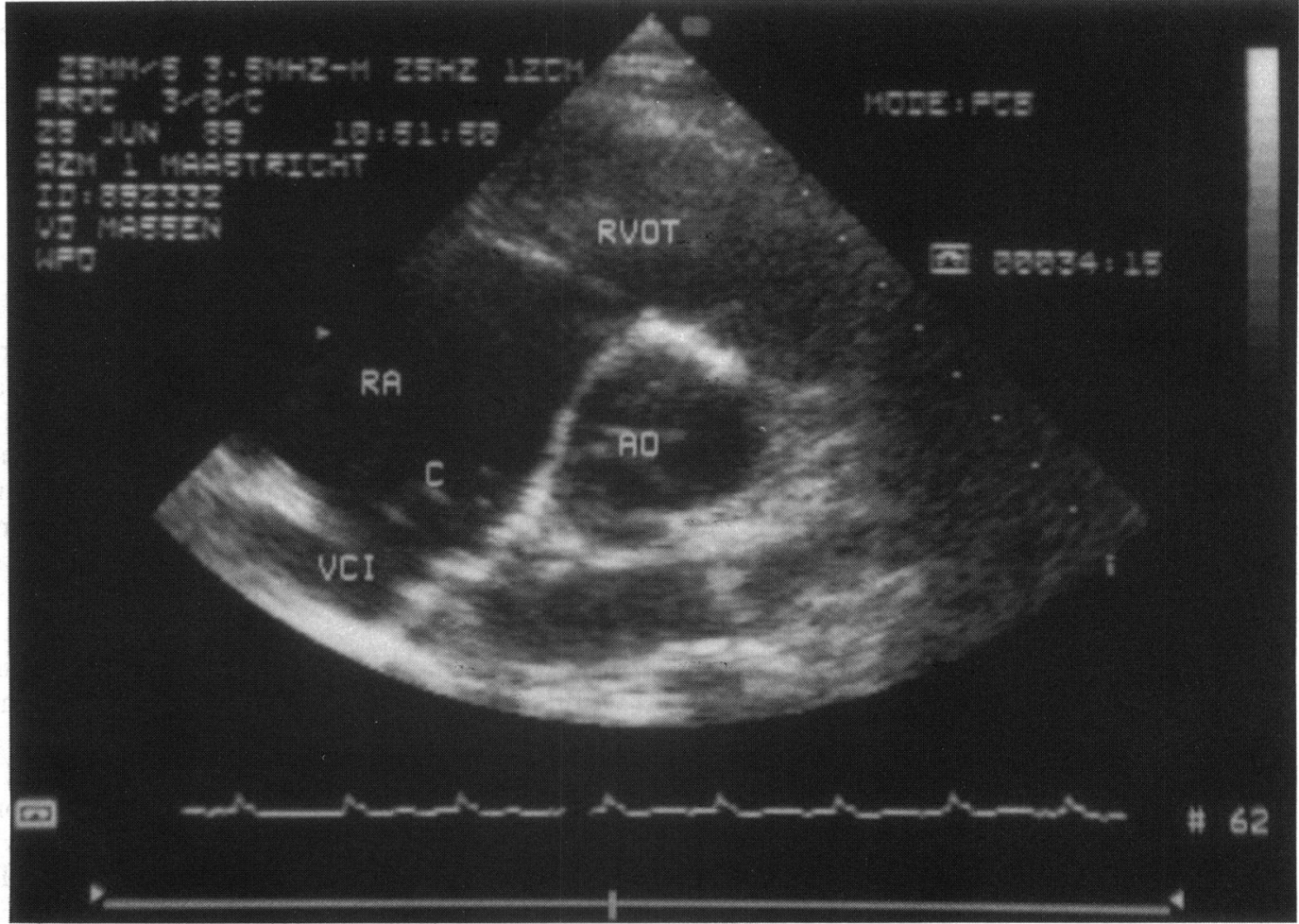

patients. ${ }^{13}$ Right ventricular failure, tricuspid incompetence, and increasing right atrial pressure are the main reasons for right to left shunting. The patient presented here is exceptional. To our knowledge an abrupt change in inter-atrial flow, from absence of any clinical shunting to severe symptomatic right to left shunting has not been reported before. In this patient cryosurgical trauma to the right atrium, causing akinesia of a considerable part could have influenced the interatrial pressure gradient.

The second unusual complication in this patient was the entrapment of a venous thrombus in the Chiari network. Entrapment

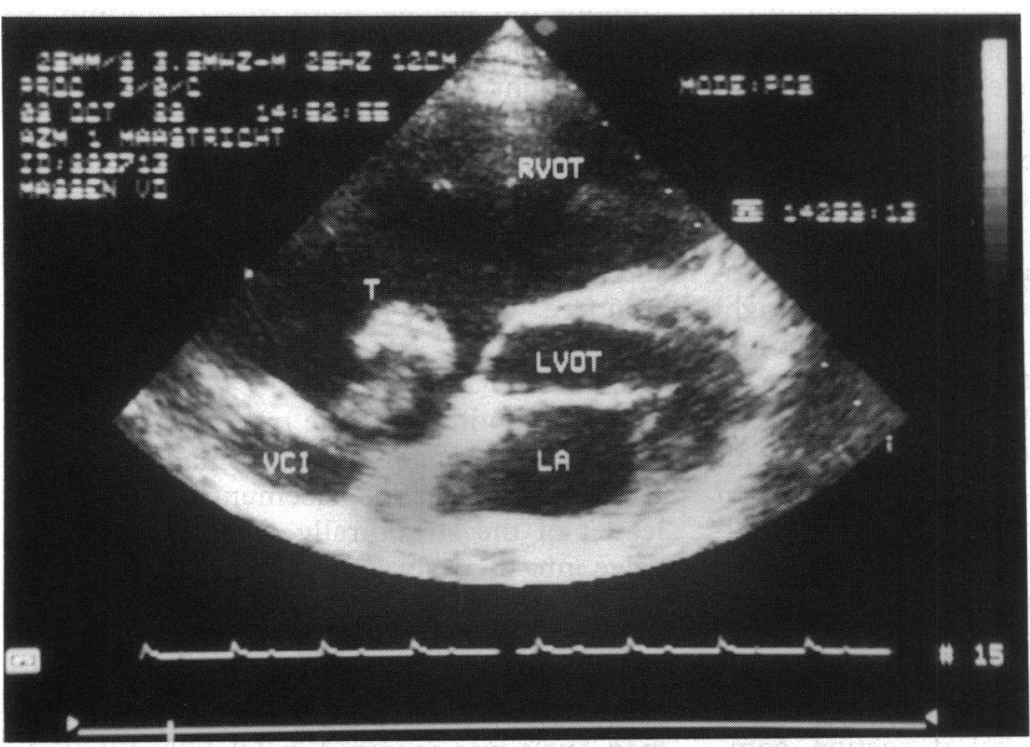

Figure 2 Transthoracic echocardiogram (parasternal short axis) showing a large thrombus (T) entrapped in the Chiari network (RVOT, right ventricular outflow tract; LVOT, left ventricular outflow tract). prevented pulmonary embolism.

Echocardiographically detected right-sided heart thrombi are uncommon. The reported mortality associated with these echocardiographically detected thrombi is $29-100 \%$. Most thrombi visualised in the right heart are parts of a larger thrombus that is still partly "fixed" in the inferior vena cava. We know of no other descriptions of thrombi entrapped in the Chiari network. Two case reports, however, describe paradoxical embolisation and pulmonary emboli in patients with Ebstein's anomaly. ${ }^{89}$ In one the thrombus was detected echocardiographically before death. ${ }^{9}$ Survival mainly depends on the prevention of pulmonary emboli. The calculated probability of survival without treatment in this patient was $50 \%$ according to the logistic regression calculation of Kinney and White. ${ }^{7}$ After three weeks of unsuccessful heparinisation the thrombus was removed surgically. We do not know why venous thrombosis developed in this patient. The Chiari network prevented the thrombus from causing pulmonary embolism. Paradoxical embolisation was not a possibility because the atrial septal defect had been closed.

1 Vacca JB, Bussmann DW, Mudd JG. Ebstein's Anomaly. Complete review of 108 cases. Am $\mathcal{F}$ Cardiol 1958;2: 210-26.

2 Kumar AE, Fyler DC, Miettinen OS, Nadas AS. Ebstein's anomaly. Clinical profile and natural history. Am f Cardiol 1971;28:84-95.

3 Bialostozky D, Horwitz S, Espino-Vela J. Ebstein's malformation of the tricuspid valve. A review of 65 cases. Am $\mathcal{C}$ Cardiol 1972;29:826-36.

4 Sealy WC Gallagher JJ, Pritchet ELC, Wallace AG. Surgical treatment of tachycardias in patients with both an Ebstein's anomaly and a Kent bundle. $\mathcal{F}$ Thorac an Ebstein's anomaly and a Ken

5 Gardiovasc Surg 1978;75:847-53. Ebstein's anomaly. The clinical features and natural history of Ebstein's anomaly of the tricuspid valve. Mistory of Ebstein's anomaly of

6 Watson $H$. Natural history of Ebstein's anomaly of tricuspid valve in childhood and adolescence. An 
international cooperative study of 505 cases. Br Heart $\mathcal{f}$ 1974;36:417-27.

7 Kinney EL, Wright RJ. Efficacy of treatment of patients with echocardiographically detected right-sided heart thrombi: A meta-analysis. Am Heart $f$ 1989;118: 569-73.
8 Mathews $\mathrm{JL}$, Pennington WS, Isobe JH, Gaskin TA, Dumas JH, Kahn DR. Paradoxical embolization with Ebstein's anomaly. Arch Surg 1983;118:1101.

9 Fornace J, Rozanski LT. Right heart thrombeombolism and suspected paradoxical embolism in Ebstein's anomaly. Am Heart f 1987;114:1520-2.

\title{
SHORT CASES IN CARDIOLOGY
}

\section{Primary hyperparathyroidism presenting as torsades de pointes}

\author{
Peter Kearney, Michael Reardon, James O'Hare
}

A previously well 47 year old woman presented to hospital complaining of syncopal episodes over the preceding 24 hours and of anorexia, nausea, polyuria, polydipsia, and generalised aches and pains for 2 weeks. She lost consciousness and her electrocardiograph showed short runs of multiform ventricular tachycardia (figure). These worsened, degenerating into ventricular fibrillation that required repeated DC cardioversion. The arrhythmia was refractory to intravenous lignocaine, magnesium, and amiodarione and stabilised only after a transvenous pacemaker set to $100 \mathrm{beats} / \mathrm{min}$ was inserted. Clinical examination was unremarkable. Serum biochemistry showed hypokalaemia $(3.1 \mathrm{mmol} / \mathrm{l})$ and hypercalcaemia $(3.12 \mathrm{mmol} / \mathrm{l})$. Twenty four hour urinary calcium was increased $(13.5 \mathrm{mmol})$ and a parathormone assay (INTACT IRMA) showed a concentration of $517 \mathrm{pg} / \mathrm{ml}$ (normal range $5-15 \mathrm{pg} / \mathrm{ml}$ ) that confirmed the diagnosis of primary hyperparathyroidism. A parathyroid adenoma weighing $2 \cdot 79 \mathrm{~g}$ was located and excised and the patient made an uneventful recovery.

Hypokalaemia, a well recognised precipitant of torsades de pointes ${ }^{1}$ is noted in approximately $5 \%$ of cases of primary hyperparathyroidism. ${ }^{2}$ It is probably a result of proximal (type II) and, to a lesser extent, type I renal tubular acidosis. Secondary hyperaldosteronism resulting from intravascular volume depletion can also occur.
Hypercalcaemia also may have contributed. The increases in heart rate and contractility caused by parathormone are thought to be the result of direct induction of calcium influx into myocardial cells and the release of endogenous myocardial adrenaline. ${ }^{3}$ Hypercalcaemia shortens the plateau phase of the action potential, leading to a shorter QT interval. Re-entry is one proposed electrophysiological mechanism underlying torsades de pointes and in this context the positive chronotropic and QT-shortening effect of parathormone might be expected to protect against the arrhythmia by decreasing intraventricular dispersion of refractoriness. Calcium administration reduced the propensity to ventricular fibrillation by shortening the QT interval in dogs. ${ }^{4}$

There is, however, also evidence that an increased calcium concentration might have an arrhythmogenic effect by enhancing early afterdepolarisations, which have more recently been hypothesised to underlie torsades de pointes.

1 Surawicz B. Electrophysiologic substrate of torsade de pointes: dispersion of repolarisation or early afterdepopointes: dispersion of repolarisation or early afte

2 Stewart AF, Broadus AE. Mineral metabolism. In: Felig P, Baxter J, Broadus A, Frohman L, eds. Endocrinology and metabolism. New York: McGraw, 1987:1396.

3 Bogin E, Massry SG, Harary I. Effect of parathormone on rat heart cells. $\mathcal{F}$ Clin Invest 1981;67:1215.

4 Murdock D, Euler D, Becker D, Murdock J, Scanion P, Gunnar R. Ventricular fibrillation during coronary angiography: an analysis of mechanisms. Am Heart 1985;109:265-73.
Electrocardiograms recorded shortly after admission. (A) Short run of multiform ventricular tachycardia follows a long $R R$ interval of the dominant cycle, starting with an $R$ on $T$ ventricular extrasystolic beat. (B) $U$ waves (indicated by arrow) and a run of multiform tachycardia with typical axis changes and variable rate. $S T$ depression may be the result of hypokalaemia and/or hypercalcaemia.

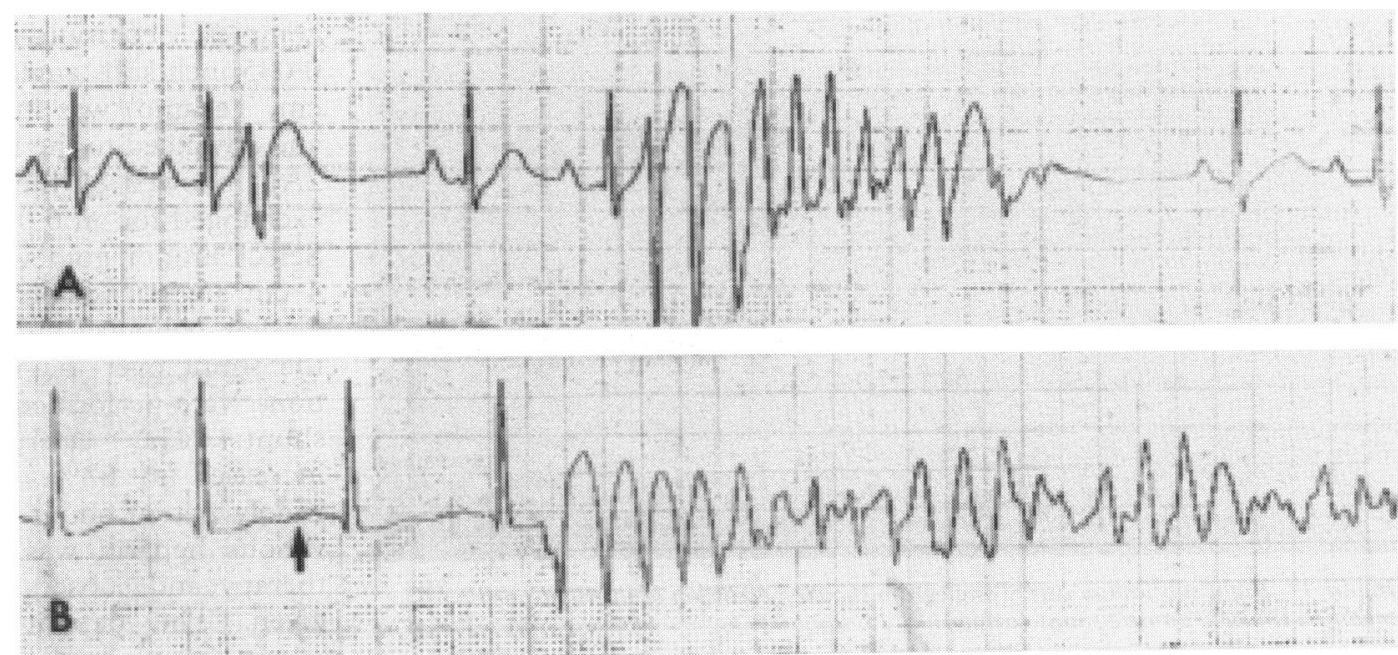

